\title{
Is single-stage resection and anastomosis for acute sigmoid volvulus, without intra operative colonic lavage a safe procedure?
}

\footnotetext{
1. MBBS, FCPS

District Surgeon DHQ Charsadda.

2. MBBS, FCPS

Associate Professor General

Surgery

LRH Peshawar.

3. MBBS, FCPS

General Surgeon

DHQ Charsadda.

4. MBBS, FCPS,

Medical Officer

DHQ Charsadda.
}

Correspondence Address:

Dr. Viqar Aslam

Department of General Surgery

LRH Peshawar.

bilalsurg@gmail.com

Article received on:

21/08/2020

Accepted for publication: 06/10/2020

\begin{abstract}
Muhammad Bilal' ${ }^{1}$, Viqar Aslam², Waqas Jan $^{3}$, Zaheerudin ${ }^{4}$
\end{abstract}
\begin{abstract}
Objective. This study was conducted to provide local data regarding the results and post-operative complications after single-stage resection and anastomosis for acute sigmoid volvulus, without intra operative colonic lavage. Study Design: Descriptive Cross Sectional. Setting: DHQ Charsadda. Period: May 2017 to December 2019. Material \& Methods: This clinical study was done on 50 patients who presented with the signs and symptoms of acute sigmoid volvulus excluding those with complications of the illness such as gangrene, perforation and peritonitis. Surgery for all patients was carried out under General anaesthesia. All the patients underwent emergency resection and primary anastomosis, without mechanical bowel preparation. Data were collected regarding post operation complication and analysis by using SPSS version 23. Chi square test was used to compare at level of significance $<0.005$. Results: Median age of patients was 50 years with male to female ratio 5:3. Seven patients presented with wound infection, one dehiscence while zero Anastomotic leakage and zero death postoperative recorded. Conclusion: Single stage resection and primary anastomosis without preoperative colonic lavage for acute sigmoid volvulus is a simpler and short procedure with low mortality and morbidity rates.
\end{abstract}

Key words: $\quad$ Anastomosis, Resection, Sigmoid Volvulus.

Article Citation: Bilal M, Aslam V, Jan W, Zaheerudin. Is single-stage resection and anastomosis for acute sigmoid volvulus, without intra operative colonic lavage a safe procedure? Professional Med J 2021; 28(6):872-875. https://doi.org/10.29309/TPMJ/2021.28.06.6017

\section{INTRODUCTION}

Sigmoid volvulus is defined as 360 anticlockwise twist of sigmoid colon on its mesentery. The management of sigmoid volvulus is still debatable. Although endoscopic or even radiological decompression with contrast enema represents the mainstay of acute control, recurrent episodes generally require surgical intervention for definitive management. Single stage surgical technique for sigmoid volvulus has many advantages like it reduces the duration at hospital stay, number of procedures etc. Although colorectal surgeons keep in mind a mechanically cleansed and empty bowel as a prerequisite for a safe colonic resection and anastomosis on the way to reduce the risk of septic complications and anastomotic dehiscence. ${ }^{1-2}$ Many studies have failed to show any superiority of mechanical bowel preparation in colorectal surgery and have questioned this practice. . $^{3-4}$
So rationale of the study is that due to lack local studies, we have to rely on evidences provided by international studies ${ }^{3-5}$ which may not be applicable to our population due to different socioeconomic circumstances, illiteracy and availability of health care services. Therefore this study was conducted to provide local data regarding to evaluate the results of singlestage resection and anastomosis for acute leftsided colonic obstruction due to acute sigmoid volvulus, without intra operative colonic lavage, postoperative complications etc So that better strategies can be planned by the surgeons to combat the problems in our population.

\section{MATERIAL \& METHODS}

It was a descriptive cross-sectional study conducted at the department of surgery DHQ hospital Charsadda after the approval of Institutional Ethical Committee (No.181/299/DHQ 
Hospital CHD Dated 12-03-17) from May 2017 to December 2019. The study was done on 50 patients who presented at the emergency unit during study duration with the signs and symptoms of intestinal obstruction excluding those with complications of the illness such as gangrene, perforation and peritonitis. The patients were selected by non-probability convenient Sampling method. Informed consent was obtained and to minimize the errors clear instructions were given to the study participants.

In all those patients a detailed history was taken which included the patient's demographics (age, gender), co-morbidities and focused mainly on the symptoms of acute intestinal obstruction such as abdominal pain, abdominal distension and constipation due to which they presented to casualty section. After thorough history all the patients underwent plain x-ray abdomen which showed dilated gut loops or a coffee bean sign that is pathognomonic for sigmoid volvulus and thus diagnosis was made with the help of both clinical and radiographic findings. Few relevant tests like blood profile, serum electrolytes, and Serum urea and urine analysis were also done.

The patients were initially resuscitated with fluid and electrolyte replacement, NG Aspiration acid base management and were catheterized (urethral) to monitor the urine output every hourly. Antibiotics were given at the induction of anesthesia and then they were continued for about 5 days. Then after giving a midline laparotomy incision the bowel viability was assessed and final diagnosis was made.

In the beginning the obstruction is relieved by untwisting the colon and then decompression of the distended bowel loop is carried out and remaining faecal particles were removed via digital milking. Swabs soaked in aqueous chlorhexidine were applied to the ends of the resected bowel and the ends were trimmed till fresh bleeding and then two layered end-to-end anastomosis was done with an inner continuous layer and an outer interrupted seromuscular layer of $3 / 0$ poldioxanone and $3 / 0$ silk respectively.
No proximal stoma was used for the protection of the anastomosis. The abdomen was closed by mass closure technique after peritoneal lavage with normal saline and draining the pelvis.

Proper documentation of the clinical course, hospital stay, postoperative complications like wound infection, anastomotic failure and mortality were made.

Statistical analysis was performed using SPSS version 23. Frequencies and percentages were calculated for categorical variables (Age, gender and comorbidities). Comparison of the procedure outcome (anastomotic dehiscence, wound infection and mortality) between double resection and anastomosis with primary resection and anastomosis was made via chi square test. Median were calculated for variable like age, hospital stay.

\section{RESULTS}

A total 50 patients who presented with uncomplicated acute sigmoid volvulus to surgical unit of DHQ Charssada were included in this study. Patients' characteristics (Age, Gender) are shown In Table-l. The age ranged from 29-73 years with median age of 50 years while for female it was 34 to 67 with median of 50 years. The numbers of male $32(64 \%)$ patients were more as compared to female patients 18 (36\%). Out of 50 patients 08 were having Hypertension and only 02 patients had Diabetes Mellitus.

Three cases were managed by double resection and ileoilealand colorectal anastomosis that experienced ileosigmoid knotting. The primary anastomosis and resection were performed on the remaining 47 subjects. According to our study the median duration of hospital stay was 12 days and postoperative hospital stay ranged from 8 to 20 days.

Only 7 patients had wound infection, one case with wound dehiscence, no anastomotic leakage and zero mortality was recorded in this study. (Table-II) 


\begin{tabular}{|l|c|c|}
\hline \multicolumn{1}{|c|}{ Age } & Male (n=32) & \multicolumn{2}{c|}{ Female (n=18) } \\
\hline Range & $29-73$ & $34-67$ \\
\hline Median & 50 & 50 \\
\hline \multicolumn{2}{|c|}{ Table-I. Age in Years (Range and Median). } \\
\hline Complications/Complaints & $\begin{array}{c}\text { Male } \\
(\mathbf{n = 3 2})\end{array}$ & $\begin{array}{c}\text { Female } \\
(\mathbf{n = 1 8})\end{array}$ \\
\hline Wound infection & $05(15.6 \%)$ & $02(11.1 \%)$ \\
\hline Wound dehiscence & $01(3.1 \%)$ & $0(0.0 \%)$ \\
\hline Anastomotic leakage & $0(0.0 \%)$ & $0(0.0 \%)$ \\
\hline Mortality & $0(0.0 \%)$ & $0(0.0 \%)$ \\
\hline
\end{tabular}

Table-II. Post-operative and follow-up complications/ complaints.

\section{DISCUSSION}

Treatment is directed to reduce and prevent the periodic episode of sigmoid volvulus. Intravenous metoclopramide and fluid infusion are given. ${ }^{6-10}$ However when endoscopic detorsion is not successful or in patients presenting with signs and symptoms indicating of peritonitis immediate laparotomy is done. Sigmoidectomy, either with primary anstomosis or colostomy is the definitive treatment. Life threatening complications eg sigmoid gangrene, perforation, peritonitis, sepsis and death may occur if not diagnosed on time. ${ }^{11-}$ 15

Surgical resection and primary anastomosis because of its good procedure outcome reports is in high demand over the past ten years. ${ }^{16}$ Non operative procedures like enema, sigmoidoscopy or rectal tube is preferred in selected patients. In highly selective patients, we do radiographic or endoscopic decompression. In cases of failure of non-surgical decompression, emergency surgery is performed. ${ }^{17-19}$

In present study patient's age ranging for male was $29-73$ and their median age was 50 years while for female it was 34 to 67 with median of 50 years. There were 32 male while 18 female with a male to female ratio 5:3. This gender imbalance was due to chance. The age of the patients of our study group was similar to the other studied done by oludiran ${ }^{20}$ and Laor. ${ }^{21}$

Like other studies ${ }^{5,8}$, no anastomotic leakage occurred in this study it may be due to patients had less co morbid, relatively fit patients, and preoperative proper management are probably responsible for this. Superficial wound infection occurred in 7 (\%) patients, which is in accordance's to that reported by Oludiran. ${ }^{20}$ One case of wound dehiscence occured. All these were treated with satisfactory outcome. There was no mortality in this study which is comparable to international studies..$^{8-9}$

In another study by Santos et $\mathrm{al}^{19}$ it was documented that whether bowel is prepared or not before elective colon surgery, it does not have any significant effect on the risk of anastomotic dehiscence. Some studies reports the drawbacks of bowel preparation such as electrolyte imbalance especially in elderly patients. ${ }^{6-9}$

So findings were that single stage resection and primary anastomosis without preoperative colonic lavage is a simpler and short procedure with low mortality and morbidity rates.

\section{CONCLUSION}

It is a safe procedure for the management of acute sigmoid volvulus. It is recommended that future studies should be carried out on a large sample size.

Copyright $@ 06$ Oct, 2020.

\section{REFERENCES}

1. lida T, Nakagaki $S$, Satoh $S$, Shimizu $H$, Kaneto $H$, Nakase H. Clinical outcomes of sigmoid colon volvulus: Identification of the factors associated with successful endoscopic detorsion. Intest Res. 2017 Apr;15(2):215-20.

2. Carmo L, Amaral M, Trindade E, Henriques-Coelho T, Pinho-Sousa J. Sigmoid volvulus in children: Diagnosis and therapeutic challenge. GE Port J Gastroenterol. 2018 Sep;25(5):264-7.

3. Mulugeta, G., Awlachew, S. Retrospective study on pattern and outcome of management of sigmoid volvulus at district hospital in Ethiopia. BMC Surg. 2019;19: 107.

4. Nasir M, Khan IA. Resection and primary anastomosis in the management of acute sigmoid volvulus. Pakistan J Surg.2008;24:95-7. 
5. Shanti Kumar G, Upender A, Ramesh Kumar D, Kalavathi S. Sigmoid volvulus and its management: A study of 38 cases. Int J Med Res Rev. 2016; 4(9):1587-90.

6. Kolbeinsson HM, Ingudottir Andresdottir BD, Hannesson $\mathrm{PH}$, Valsdottir EB, Moller $\mathrm{PH}$. Sigmoid volvulus at the University Hospital of Iceland 2000-2013. Laeknabladid. 2018 Sep; 104(79):391-394.

7. Baiu I, Shelton A. Sigmoid Volvulus. JAMA. 2019 Jun $25 ; 321(24): 2478$.

8. Perrot L, Fohlen A, Alves A, Lubrano J. Management of the colonic volvulus in 2016. J Visc Surg. 2016 Jun; 153(3):183-92.

9. Ballard DH, Samra NS. Massive sigmoid volvulus. Surgery. 2016 Aug; 160(2):521-2.

10. Selvaraj DR, Palaniswamy C. Sigmoid volvulus. J Hosp Med. 2010 Apr; 5(4):E36-7.

11. Atamanalp SS. Re: Recurrent sigmoid volvulus in pregnancy. ANZ J Surg. 2018 Mar; 88(3):250-251.

12. Atamanalp SS. Comments on contemporary management of sigmoid volvulus. J Gastrointest Surg. 2019 Feb; 23(2):391-392.

13. Volvulus. Bauman ZM, Evans $\mathrm{CH}$. Surg Clin North Am. 2018 Oct; 98(5):973-993.

14. Purcell LN, Reiss R, Mabedi C, Gallaher J, Maine R, Charles $A$. Characteristics of intestinal volvulus and risk of mortality in Malawi. World J Surg. $2020 \mathrm{Jul}$; 44(7):2087-2093.
15. Bajaj M, Gillespie C, Dale J. Response to Re: Recurrent sigmoid volvulus in pregnancy. ANZ J Surg. 2018 Apr; 88(4):385.

16. Cornman-Homonoff J, Milsom JW, Schiffman $\mathrm{MH}$. Management of recurrent sigmoid volvulus via nontransmural percutaneous colon fixation. $\mathrm{J}$ Vasc Interv Radiol. 2019 Oct; 30(10):1669-1671.

17. Atamanalp SS. Sigmoid volvulus: Effects of high altitude. Colorectal Dis. 2018 Sep; 20(9):825-826.

18. Bruzzi $M$, Lefèvre JH, Desaint $B$, Nion-Larmurier I, Bennis M, Chafai N, Tiret E, Parc Y. Management of acute sigmoid volvulus: Short- and long-term results. Colorectal Dis. 2015 Oct; 17(10):922-8. doi: 10.1111/ codi.12959. PMID: 25808350.

19. Santos JCM Jr, Baitista J, Sirimarco MT, Guimares AS, Levy CE. Prospective randomized trial of mechanical bowel preparation in patients undergoing elective colorectal surgery. Br J Surg 1994; 81: 1673-6.

20. Oludiran OO, Osime OC. Emergency one-stage resection without mechanical bowel preparation for acute sigmoid volvulus. J Med and Biomed Res 2004; 3(1): 86-90.

21. Laor A, Tal S, Guller V, Zbar AP, Mavor E. The Charlson comorbidity index $(\mathrm{CCl})$ as a mortality predictor after surgery in elderly patients. Am Surg. 2016 Jan; 82(1):22-7.

\begin{tabular}{|c|c|c|c|}
\hline \multicolumn{4}{|c|}{ AUTHORSHIP AND CONTRIBUTION DECLARATION } \\
\hline Sr. \# & Author(s) Full Name & Contribution to the paper & Author(s) Signature \\
\hline 2 & $\begin{array}{l}\text { Muhammad Bilal } \\
\text { Viqar Aslam } \\
\text { Waqas Jan } \\
\text { Zaheerudin }\end{array}$ & $\begin{array}{l}\text { Data collection, Analysis, Literature } \\
\text { review. } \\
\text { Research designing, Literature } \\
\text { review and drafting. } \\
\text { Objective setting, Drafting. } \\
\text { Data collection, Paper write-up. }\end{array}$ & $\begin{array}{l}\text { MApaul } \\
\text { Vashom } \\
\text { Zahear } \\
\text { Wagas: }\end{array}$ \\
\hline
\end{tabular}

